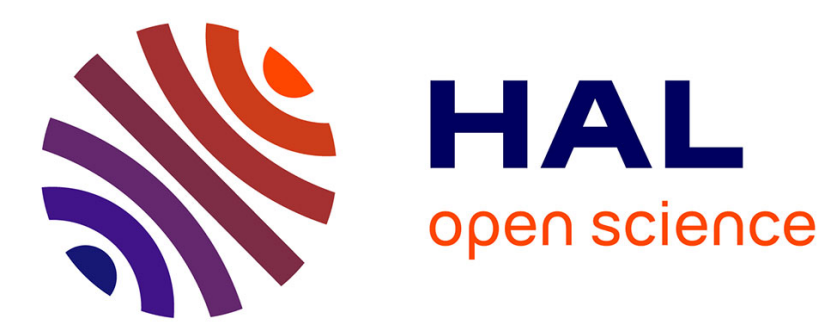

\title{
Processing, repairing and cyclic oxidation behaviour of sol-gel thermal barrier coatings
}

Lisa Pin, Florence Ansart, Jean-Pierre Bonino, Yannick Le Maoult, Vanessa Vidal, Philippe Lours

\section{- To cite this version:}

Lisa Pin, Florence Ansart, Jean-Pierre Bonino, Yannick Le Maoult, Vanessa Vidal, et al.. Processing, repairing and cyclic oxidation behaviour of sol-gel thermal barrier coatings. Surface and Coatings Technology, 2011, vol. 206, pp. 1609-1614. 10.1016/j.surfcoat.2011.06.043 . hal-00862288

\section{HAL Id: hal-00862288 \\ https://hal.science/hal-00862288}

Submitted on 16 Sep 2013

HAL is a multi-disciplinary open access archive for the deposit and dissemination of scientific research documents, whether they are published or not. The documents may come from teaching and research institutions in France or abroad, or from public or private research centers.
L'archive ouverte pluridisciplinaire HAL, est destinée au dépôt et à la diffusion de documents scientifiques de niveau recherche, publiés ou non, émanant des établissements d'enseignement et de recherche français ou étrangers, des laboratoires publics ou privés. 


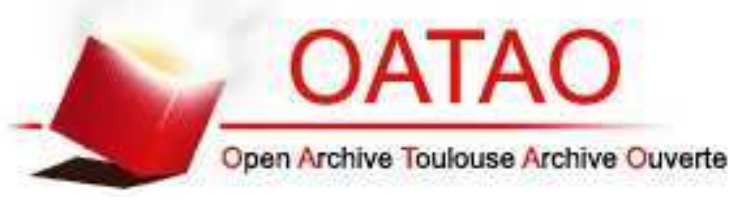

\section{Open Archive TOULOUSE Archive Ouverte (OATAO)}

OATAO is an open access repository that collects the work of Toulouse researchers and makes it freely available over the web where possible.

This is an author-deposited version published in : http://oatao.univ-toulouse.fr/ Eprints ID : 8693

To link to this article : DOI:10.1016/j.surfcoat.2011.06.043

URL : http://dx.doi.org/10.1016/j.surfcoat.2011.06.043

To cite this version : Pin, Lisa and Ansart, Florence and Bonino, JeanPierre and Le Maoult, Yannick and Vidal, Vanessa and Lours, Philippe. Processing, repairing and cyclic oxidation behaviour of solgel thermal barrier coatings. (2011). Surface and Coatings

Technology, vol. 206 ( $\mathrm{n}^{\circ}$ 7). pp. 1609-1614. ISSN 0257-8972

Any correspondance concerning this service should be sent to the repository administrator: staff-oatao@ listes-diff.inp-toulouse.fr 


\title{
Processing, repairing and cyclic oxidation behaviour of sol-gel thermal barrier coatings
}

\author{
Lisa Pin ${ }^{\mathrm{a}, \mathrm{b}}$, Florence Ansart ${ }^{\mathrm{b}}$, Jean-Pierre Bonino ${ }^{\mathrm{b}}$, Yannick Le Maoult ${ }^{\mathrm{a}}$, Vanessa Vidal ${ }^{\mathrm{a}}$, Philippe Lours ${ }^{\mathrm{a}, *}$ \\ a Université de Toulouse, Mines Albi - Institut Clément Ader, Campus Jarlard, 81013 Albi, France \\ ${ }^{\mathrm{b}}$ Université de Toulouse, CIRIMAT-UPS, 31062 Toulouse, France
}

Keywords:

Thermal barrier coating

Sol-gel processing

Cyclic oxidation

Spallation

In situ investigation

Repair process

\begin{abstract}
A B S T R A C T
Sol-gel Thermal Barriers Coatings (TBCs) are manufactured using the dip-coating technique optimised in terms of process parameters including sol formulation, rate of withdrawing and heat treatment. The specific mechanisms of sol-gel TBCs, deposited on either NiAl or NiPtAl bond-coated superalloy substrates, are described. The possibility to reinforce and stabilise the crack network formed during the heat treatment or the first oxidation cycles using supplementary dip-coatings and appropriate process parameters is investigated. It is shown that implementing this technique that can be further regarded as an attractive way for repairing TBCs, significantly improves the cyclic oxidation behaviour of the multi-materials systems.
\end{abstract}

\section{Introduction}

Thermal Barrier Coatings (TBCs) constitute the external scale of functional, complex multi-materials systems used to insulate hot section parts from the high temperature gases in aircraft engines gas turbines. Added to internal cooling systems applied to blades, vanes and other parts of gas turbines, TBCs can decrease the component service temperature down to more than $150^{\circ} \mathrm{C}$. As a consequence, the turbine inlet temperature can be significantly increased to improve engine efficiency while reducing NOx emission with no impact on components durability. Prior to deposit the TBC, nickel base superalloy substrates are bond coated either with alumina forming NiAl, NiPtAl or with MCrAlY [1,2]. Today, industrial manufacturing of TBCs is mainly carried out using two physical processes, namely the Electron Beam Physical Vapour Deposition (EB-PVD) and the Atmospheric Plasma Spraying (APS). EB-PVD results in columnar TBCS showing fairly good lateral compliance while APS allows the deposition of lamellar TBCs, less resistant to the detrimental effect of thermomechanical stresses but with about twice lower conductivity, in the range $0.7-0.9 \mathrm{~W} \cdot \mathrm{m}^{-1} \cdot \mathrm{K}^{-1}$.

The new promising and versatile sol-gel process has proved to be efficient for depositing yttria-stabilised zirconia (YSZ) thermal barrier coatings on top of multi-materials systems composed of superalloys substrates, $\mathrm{NiAl}$ or NiPtAl bond coats and alumina thermally grown oxides. Processing such TBCs by the so-called dip-coating route results

\footnotetext{
* Corresponding author. Tel.: + 335634930 78; fax: + 33563493242 E-mail address: philippe.lours@mines-albi.fr (P. Lours).
}

in depositing either thin or thick, fairly adherent coatings showing non oriented microstructures with randomly structured pore network [3]. This specific microstructure confers to the barrier an optimum compromise between a satisfactory low thermal conductivity to properly insulate the system and a good lateral compliance to accommodate without fracture the thermomechanical stresses generated in service. After soft chemical processing has been completed, sintering of the TBC is ensured by a controlled heat treatment. For TBCs, typically thinner than $60 \mu \mathrm{m}$, sintering does not provoke any morphological change. However, for thicker TBC, this thermal treatment generates the formation of a fairly regular surface crack network as a result of the biaxial loading due to the ceramic shrinkage.

First, a rapid review of the mechanisms of a $60 \mu \mathrm{m}$ thick sol-gel TBCs damage resulting from the cyclic high temperature exposure is presented. Generally speaking, the behaviour upon cyclic oxidation of the TBC strongly depends on the characteristics of the initial crack network that can further enhance under the detrimental effects of the thermomechanical stresses generated by the cumulative cycles. Ultimately, the development of cracks that may perfectly connect to each other can provoke the detachment of individual zirconia particles resulting in the onset for spallation and catastrophic failure of the TBC [4]. A particular attention is paid to the synergetic effect of TBC cracking and TBC spallation whose competition results in the cyclic degradation of the coatings.

Focus is then placed on the influence of the heat treatment parameters such as the heating and cooling rates and the holding time at dwell temperature, on the geometrical characteristics of the crack network that control the behaviour of $100 \mu \mathrm{m}$ thick TBCs under loading. Subsequently, optimised TBCs are cyclically oxidised in a 
specially designed rig instrumented to monitor in situ the surface evolution resulting from the damaging cooling sequences of cumulated cycles [5]. The evolution of the degradation versus the number of 1 hour cycles at $1100{ }^{\circ} \mathrm{C}$ through the development of cracks and spalls is investigated using complementary approaches including SEM, CCD image extraction plus image analysis and laser interferometry. Finally, the possibility to proceed to the filling of either the initial or the cyclic oxidation induced crack network is investigated as a mean to properly prepare TBCs prior to thermal loading or to repair TBCs after degradation.

\section{Processing and characterization of sol-gel thermal barrier coatings}

AM1 superalloys substrates are initially covered with either NiAl bond coat or NiAl plus Pt bond coat to further enhance TBC adhesion. To process Thermal Barrier Coatings by the so-called sol-gel route, precursor YSZ sol with a composition of $9.7 \mathrm{~mol} \%$ yttria, is synthetised from zirconium (IV) propoxide $\mathrm{Zr}(\mathrm{OPr})_{4}$ (Aldrich) and yttrium (III) nitrate hexahydrate (Acros Organics) as raw materials [6]. Acetylacetone (AcAc) is used as complexing agent to reduce the hydrolysis rate of zirconium alkoxide [7], and the solvent is 1-propanol. Volume ratios between $\mathrm{AcAc}$ and $\mathrm{Zr}(\mathrm{OPr})_{4}$ and between $\mathrm{H}_{2} \mathrm{O}$ and $\mathrm{Zr}(\mathrm{OPr})_{4}$ are respectively 0.8 and 9.5 and zirconium concentration is kept constant at $0.5 \mathrm{~mol} . \mathrm{L}^{-1}$. Such a sol is used to produce YSZ powder, obtained after an operation of supercritic drying of it in the supercritic conditions of the propanol used as solvent [8]. After this step, an aerogel is first obtained. Ultimately, the powder is heat treated at $700{ }^{\circ} \mathrm{C}$. YSZ powders are dispersed into a slurry composed of the starting sol $\left(9.7 \mathrm{~mol} \% \mathrm{YO}_{1.5}\right)$ loaded with $40 \mathrm{wt} . \%$ of powder directly issued from the supercritic drying described above. Then, superalloy substrates are dipped into the slurry and withdrawn at a thoroughly controlled rate $(250 \mathrm{~mm} / \mathrm{min})$ to shape the coatings. This elementary operation is repeated until the required TBC thickness is reached and the deposit of the TBC is completed. Finally, processed specimens are heated at $1100{ }^{\circ} \mathrm{C}$ with appropriate heating and cooling rates as well as dedicated holding time that will both be detailed in Section 3 . Processing results in the deposit of fairly dense and adherent TBC layer as shown in Fig. 1.

To address surface topography of the as-processed as well as the cyclically oxidised and damaged TBC and to quantify both the depth and the width of cracks and possible spalls, confocal interferometry microscope, with a dynamic range $15 \mathrm{~nm}-350 \mu \mathrm{m}$ is used. Cyclic oxidation tests are performed in a specific dedicated automated rig instrumented with CCD camera to monitor in a real time basis the evolution of the specimen surface upon the air-forced 5 min cooling following the various cumulated 5 min heating plus 1 -hour holding at $1100^{\circ} \mathrm{C}$. Individual $\mathrm{CCD}$ images are extracted from the video recording to be treated using image analysis software. The surface

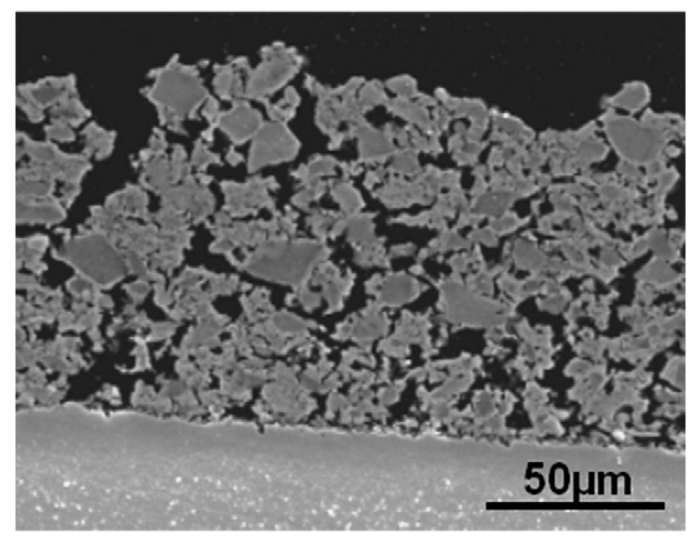

Fig. 1. SEM cross-section of a sol-gel TBC. fraction of both cracks and spalls are derived as a function of time following each cycle to derive the elementary spallation kinetics and as a function of the number of cumulated cycles to approach the overall surface damage evolution.

\section{Mechanisms of sol-gel thermal barrier coatings degradation}

As a consequence of holding sol-gel TBCs at $1100{ }^{\circ} \mathrm{C}$ during the initial heat treatment, a cracks network can develop within the coating as the result of the biaxial thermal stresses arising from the high temperature exposure and associated sintering constrained by the substrate. The extent and morphology of those cracks are strongly dependent on the thickness of the barrier. As a matter of fact, for very thin TBC almost no crack is visible but beyond a given thickness, namely higher than $60 \mu \mathrm{m}$, initial cracking prevails and acts as a precursor to a further damage of the TBC. Damage develops through the coalescence of the initial cracks essentially disconnected at the initial stage prior to exposure to cyclic oxidation. This results in the formation of a connected network generated by the percolation of individual cracks whose extent tends to level off as internal stress is fully released following the completion of crack propagation. This mechanism leads to the delamination of individual TBC cells prone to spall upon further exposure to the next oxidation cycles. The extent of cracking and spallation is also enhanced as the oxidation temperature is increased. As to illustrate these specific damage mechanisms, Fig. 2 shows the evolution of the surface fraction of cracks and spalls as a function of the oxidation temperature and the number of 1-hour cycles for a $60 \mu \mathrm{m}$ sol-gel TBC deposited on NiPtAl bond coat. At $1100{ }^{\circ} \mathrm{C}$, almost no spallation is suffered by the TBC after 551 -hour cycles while the surface fraction of crack reaches about $3.2 \%$. For oxidation at $1150{ }^{\circ} \mathrm{C}$, degradation is much pronounced as surface fractions of cracks and spalls reach respectively $3.5 \%$ and $22.7 \%$.

\section{Optimisation of the thermal treatment of sol-gel thermal barrier coatings}

As indicated above the occurrence of a thickness dependent crack network within the deposited sol-gel TBC stands for the microstructural feature that can initiate the dramatic degradation of the surface coating as the multi-layered system is subject to cyclic oxidation. The higher the thickness of the TBC, the more pronounced is the extent of the cracks. Limiting the extent of the initial crack network should probably improve the durability of the TBC to the detrimental effect of the cyclic thermomechanical loading resulting from high temperature oxidation. Indeed, the time scale for the formation and development of cracks corresponds to an incubation time during which no catastrophic spallation occurs. As a result, delaying the crack propagation progress is a way to increase life of TBC. Standard treatment at $1100{ }^{\circ} \mathrm{C}$ for $2 \mathrm{~h}$ includes quick heating and cooling rates, namely $100^{\circ} \mathrm{C} . \mathrm{h}^{-1}$. In order to adjust the parameters of the heat treatment, thick TBC $(300 \mu \mathrm{m})$ prone to enhance cracking mechanism has been produced and examined after standard treatment. Fig. 3a and b show the impact of lowering both the heating and cooling rates down to $50{ }^{\circ} \mathrm{C} \cdot \mathrm{h}^{-1}$ on the morphology of the crack network and the overall adherence of the TBC prior to any oxidation cycle. For such a high TBC thickness, high heating and cooling rate results in an extensive crack occurrence that typically provoke the partial detachment of the barrier over large area greater than $1 \mathrm{~mm}^{2}$. Conversely, TBC treated with lower heating and cooling rate exhibits a much better adherence as no spallation occurs. The crack network, unavoidably formed, is fairly regular and the size of individual spalls ranges between 25 and $50 \mu \mathrm{m}$. For TBC with lower thickness, i.e. $100 \mu \mathrm{m}$, no spallation was detected whatever the heating and cooling rates are (Fig. $3 \mathrm{c}$ and d). Note however that the standard treatment results in the formation of cracks with fairly high width and correlatively fairly high depth (Fig. 3c). As a comparison, the TBC heated and cooled at $50^{\circ} \mathrm{C} . \mathrm{h}^{-1}$ shows a more dense microstructure with lower width and depth and 


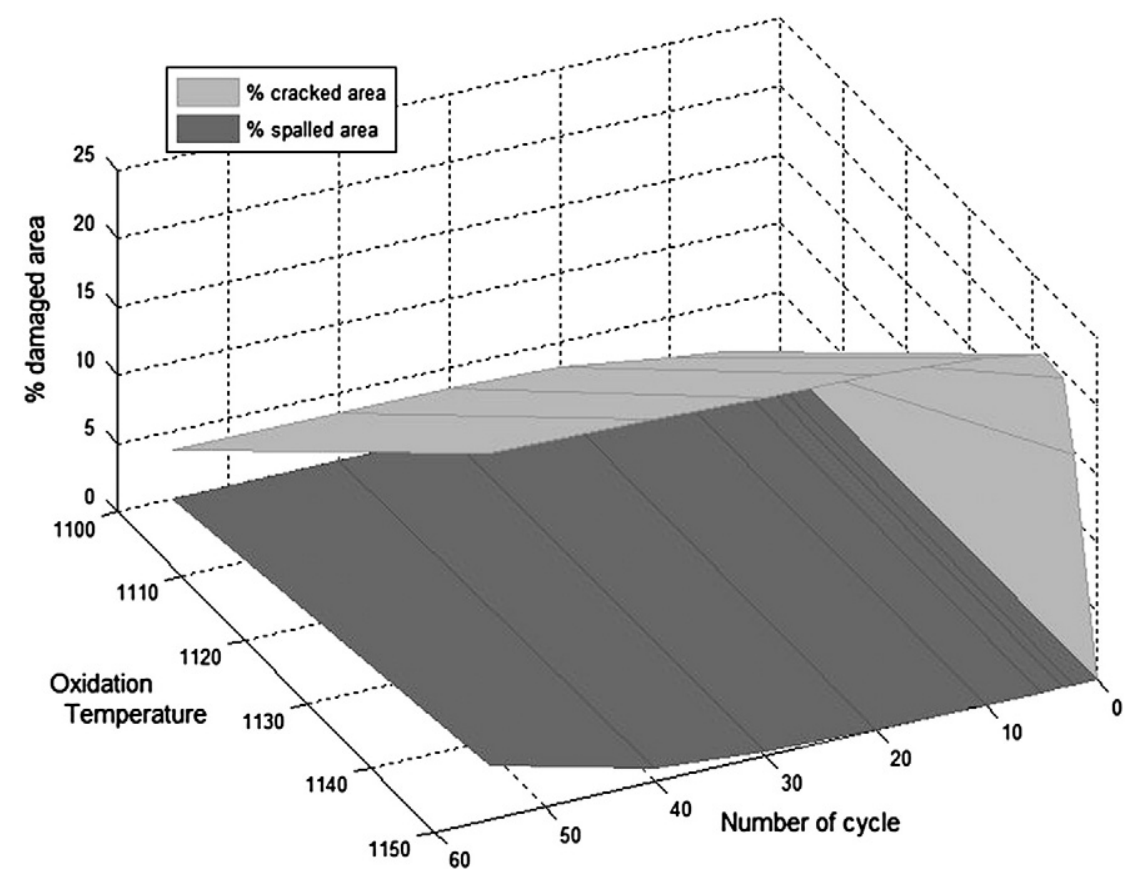

Fig. 2. Extent of cracking and spallation for a cyclically oxidised $60 \mu \mathrm{m}$-thick sol-gel TBC versus the oxidation temperature and the number of 1 -hour cycles.

smaller individual cells as well, leading to a microstructural morphology with expected enhanced adherence properties (Fig. 3d). For a given thickness, the response of the TBC to crack initiation and propagation is straightforwardly related to the capability of the material to release stress via creep deformation, which is drastically reduced for high heating and cooling rates. In this case, the lack of stress accommodation results in either extensive propagation of wide opened cracks or even, for thick TBC, full spallation of large parts of the system. This confirms the importance of the rate of heating and cooling for the constrained densification [9].

a)

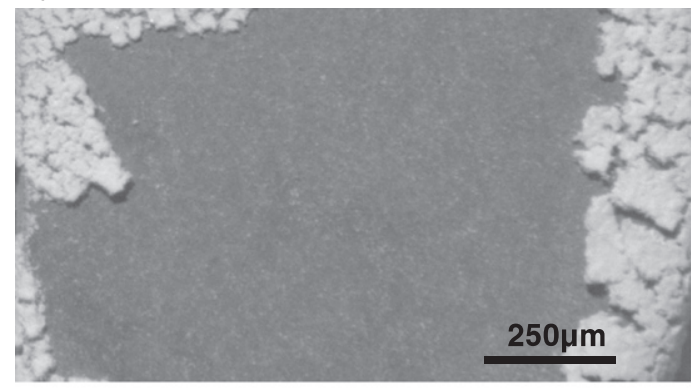

c)

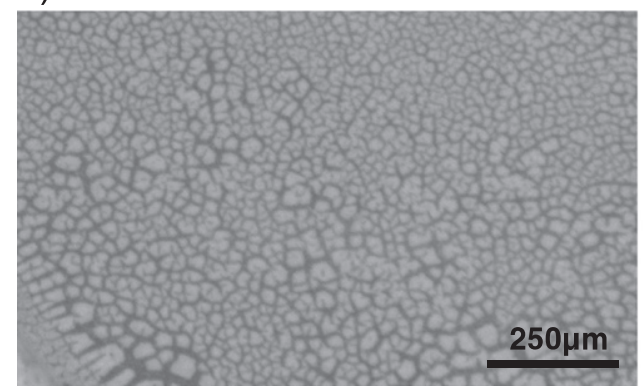

\section{Cyclic oxidation of optimised sol-gel thermal barrier coatings}

Cyclic oxidation tests were performed at $1100^{\circ} \mathrm{C}$ on both $\mathrm{NiAl}$ and NiPtAl bond-coated superalloy substrate with $100 \mu \mathrm{m}$ thick sol-gel TBC top layer prepared using the optimised low heating and cooling rates heat treatment $\left(50{ }^{\circ} \mathrm{C} \cdot \mathrm{h}^{-1}\right)$ described in Section 4. Due to their fairly high thickness, specimens have released any initial process induced internal stress by developing a regular crack network to result in the morphology shown in Fig. 3d. The surface fraction of spalls was measured after specimens were cooled down to room temperature b)

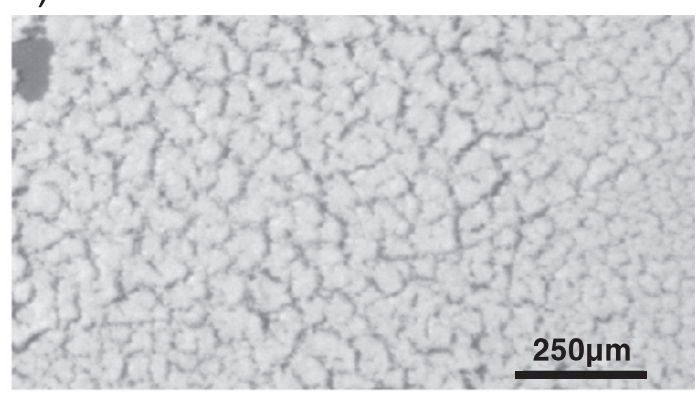

d)

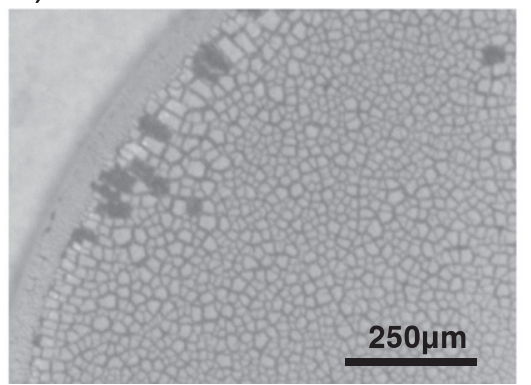

Fig. 3. Influence of the heating and cooling rate during initial heat treatment at $1100{ }^{\circ} \mathrm{C}$ for $2 \mathrm{~h}$ on the initial crack/spall damage of the TBC a) $300 \mu \mathrm{m}$ thick $\mathrm{TBC}$ and $100{ }^{\circ} \mathrm{C} . \mathrm{h}^{-1} \mathrm{~b}$ ) $300 \mu \mathrm{m}$ thick TBC and $\left.50{ }^{\circ} \mathrm{C} . \mathrm{h}^{-1} \mathrm{c}\right) 100 \mu \mathrm{m}$ thick TBC and $\left.100^{\circ} \mathrm{C} \cdot \mathrm{h}^{-1} \mathrm{~d}\right) 100 \mu \mathrm{m}$ thick TBC and $50^{\circ} \mathrm{C} . \mathrm{h}^{-1}$. 


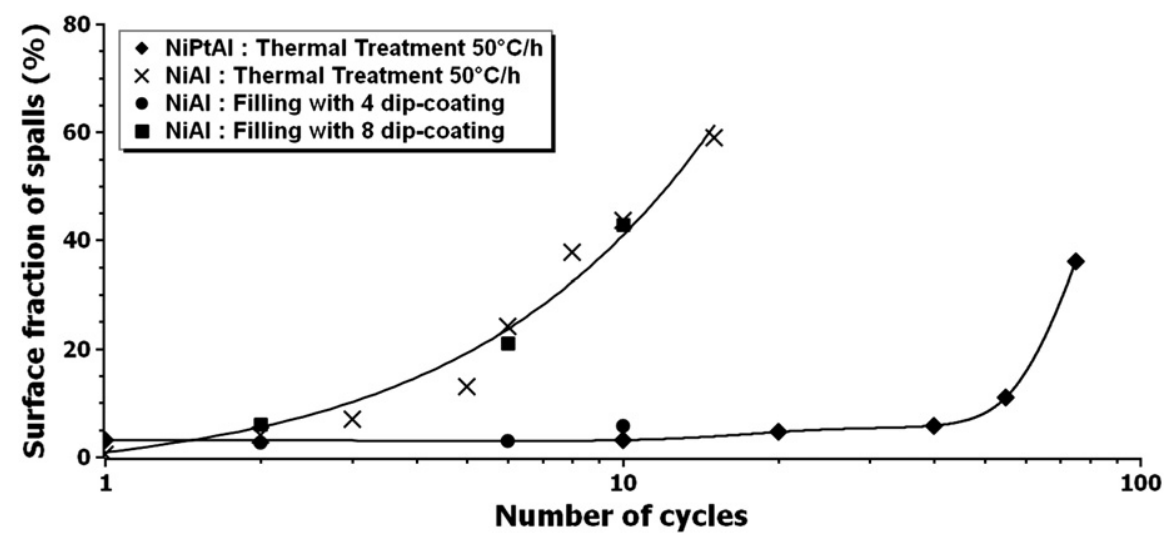

Fig. 4. Surface fraction of spalled versus the number of i) 1 hour cycles for NiAl and NiPtAl bond-coated AM1 superalloys substrates covered with sol-gel TBCs (solid lines), ii) filled in NiAl bond coated AM1 superalloys substrates with 4 and 8 additional dip-coatings (solid squares and circles).

following successive oxidation cycles. Such data are derived from the analysis of the complete spallation kinetics monitored during the cooling phases following each individual oxidation cycle. Roughly, those kinetics exhibit a typical pseudo-sigmoidal shape showing first an incubation time of approximately $240 \mathrm{~s}$ where almost no spall can be detected, followed, as the onset of spallation is reached, by a phase of extensive damage ending to a final degradation ranging from $9 \%$ to $15 \%$ surface fraction of TBC detached from the substrate. The extent of spallation is plotted versus the number of cycles in Fig. 4. As expected, note that the NiAl bond-coated specimen is more prone to spallation than the NiPtAl counterpart. In this case, the surface fraction of spalls reaches almost $60 \%$ after only 151 -hour cycles whereas for specimens with Pt addition in the bond coat, up to 75 cycles result in only $36 \%$ spallation. This confirms unambiguously the benefit of Pt to enhance adhesion of TBC elsewhere reported for standard EB-PVD TBCs [10-13]. From the individual spallation kinetics for which temperature decrease is systematically measured, it is possible to plot the surface fraction spalled against the temperature drop $\Delta \mathrm{T}$ from the oxidation temperature, i.e. $1100^{\circ} \mathrm{C}$. Fig. 5 shows the evolution of the surface degradation upon cooling after the third, sixth, eighth, twelfth and fourteenth oxidation cycle indicating that a rather low temperature is required to initiate spallation. Indeed $\Delta \mathrm{T}$ must reach about $1040^{\circ} \mathrm{C}$ to $1070^{\circ} \mathrm{C}$, that is a temperature close to ambient temperature $\left(60^{\circ} \mathrm{C}-30^{\circ} \mathrm{C}\right)$ where the energy release rate is maximum as numerically assessed in [14]. Note that this critical temperature drop to initiate spallation is very close for the various investigated cycles indicating that cumulative heating/oxidation/cooling cycles do not impact so much, at least up to the fourteenth cycle, the capability of the system to resist degradation.

\section{Sol filling of sol-gel thermal barrier coatings as a repair process for cracks and spalls}

Previous investigations [15] have shown that, subsequently to standard manufacturing and after final drying, performing additional dip-coatings of as deposited sol-gel TBCs with an appropriate slurry is an attractive way to fill in process-induced cracks. This can be regarded as highly profitable for preparing TBCs prior to be cyclically oxidised. Accordingly, this modified sol-gel route would benefit both from the stress release arising from the occurrence of the initial postdrying crack network and the strengthening provided by the postprocessing slurry filling. Additionally, filling can be used on damaged TBCs with enhanced crack network as developed during cyclic oxidation exposure and possibly resulting in the detachment of zirconia or zirconia plus alumina particles in the shape of individual spalls. Depending on the viscosity of the sol, i.e. the amount of powder loaded in the sol (previously called slurry) and the number of additional dip-coatings, the efficiency of the filling procedure can significantly vary. Loading sol with $20 \mathrm{wt} . \%$ of yttrium stabilised zirconia powder stands for the best compromise between satisfactory capillary action and appropriate viscosity. Fig. 5 is a confocal microscope view of a $1 \mathrm{~mm}^{2}$ zone of a sol-gel TBC showing the morphology of an initial crack network including a large spalled area, i) initially produced after processing and sintering (Fig. 6a) and following 4 additional dip-coatings with 20 wt.\% loaded sol (Fig. 6b). As a matter of fact, both width of the cracks and the overall size of the spall are significantly lowered after additional dip-coatings indicating that sol satisfactorily fills the defects. Only a very slight overspreading

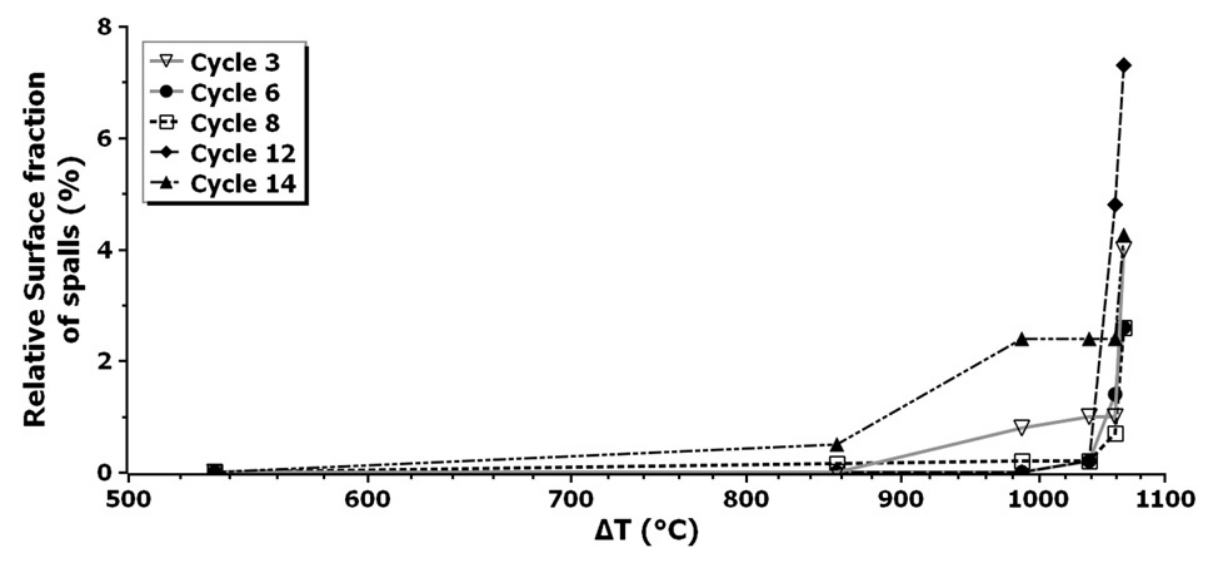

Fig. 5. Extent of spallation following cooling and determination of the critical drop for spallation. 
a) initial

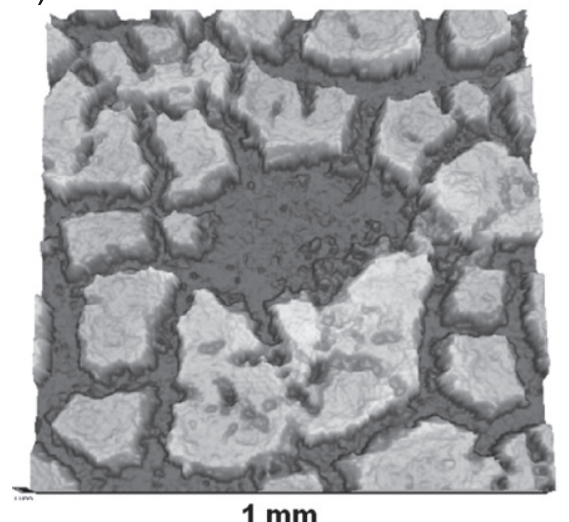

c) initial

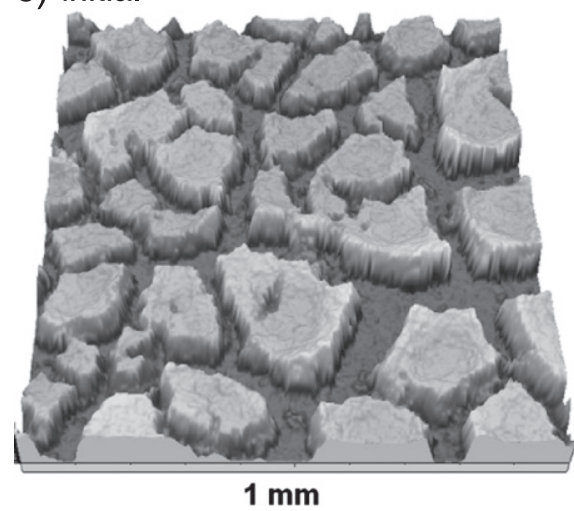

b) after four dip-coatings

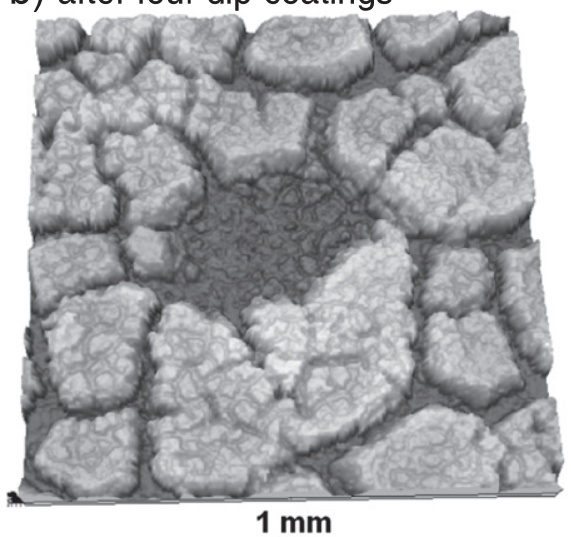

$1 \mathrm{~mm}$

d) after eight dip-coatings

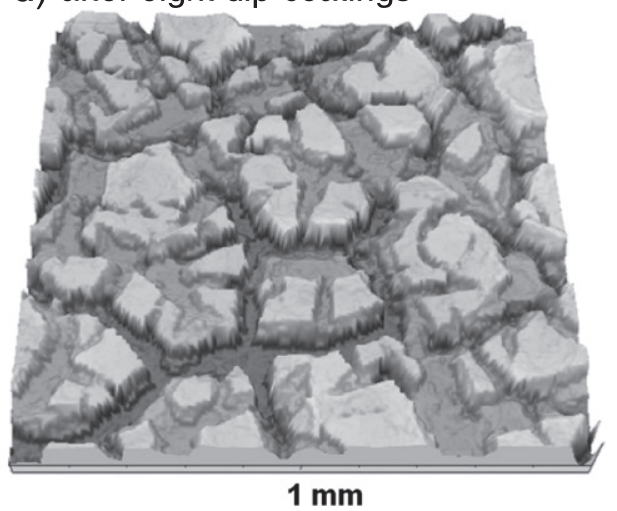

Fig. 6. Effect of additional dip-coatings on the filling of cracks.

of the rest of the barrier, outwards the cracks and spalls, by the brought up sol is visible. It is estimated to range between $2 \mu \mathrm{m}$ and $5 \mu \mathrm{m}$. In the case where further dip-coatings are conducted to possibly enhance crack filling, this over thickness resulting from the supplementary matter brought to the surface of the system by dip-coating may reach $20 \mu \mathrm{m}$. This is not acceptable as this overlaying scale is expected to exhibit fairly poor adhesion on top of the initial deposited TBC. This feature is illustrated in Fig. $6 c$ and $d$ that compares an initial cracked morphology to its counterpart with 8 additional dip-coatings. It clearly appears that the filling of the initial cracks, addressed by estimating the width of the defects, is drastically reduced. But following such a large number of dip-coatings, the TBC suffers an increase in thickness detrimental to a proper use in service. The principle for appreciating gain in reducing crack width is detailed in
Fig. 7 where the variation of the crack depth $(\Delta z)$ is plotted versus the distance over which the topological profile is determined. Graph represents the initial profile (dotted grey line) and the profile after 4 dip-coatings (solid line). As indicated above, the over thickness resulting from those four dip-coatings remains largely lower than $5 \mu \mathrm{m}$. Generally speaking, the relative shortening of the cracks is measured at the basis of the defect and is expressed as $\left(\Delta \mathrm{L} / \mathrm{L}=\mathrm{L}_{0}\right.$ $-\mathrm{L}_{\mathrm{i}} / \mathrm{L}_{0}$ ) where $\mathrm{L}_{0}$ and $\mathrm{L}_{\mathrm{i}}$ are respectively the initial width and the width after $i$ dip-coatings. Note that in the cases of two and four dipcoatings, $\Delta \mathrm{L} / \mathrm{L}=40 \%$, indicating that both procedures show similar efficiency to fill in cracks and result both in a significant relative decrease in crack opening. Increasing the number of dip-coatings should result indeed in a better closing of cracks. As a matter of fact, the relative decrease in crack width may reach almost $60 \%$ for eight

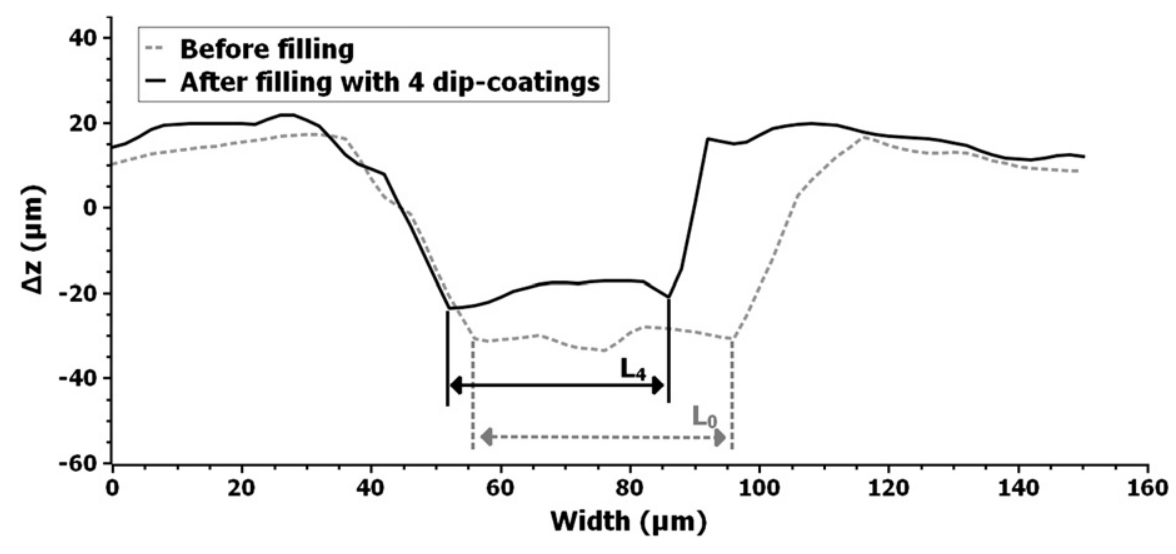

Fig. 7. Crack profile before and after filling. 
dip-coatings. However, topographic profiling unambiguously reveals that this promising result for 8 dip-coatings suffers an important limitation related to the existence of a non-adherent over layer prone to detach easily upon cyclic oxidation. The asymmetric filling profile shown in Fig. 7 is due to the directional character of the dip-coating method. Consequently, in order to avoid or limit this artefact, it would be highly interesting to further investigate other deposition processes such as spray-coating for example (keeping constant the formulation of the slurry).

Filled in TBCs with NiAl bond coats were cyclically oxidised at $1100^{\circ} \mathrm{C}$ according to the thermal profile defined in Section 2. Results are reported in Fig. 4 as the full-square and full-circle additional dots corresponding to two, six and ten cumulative cycles. Specimen filled with 4 dip-coatings shows a well better behaviour than the unfilled as-coated specimen. The extent of spallation of the filled-in NiAl is only $3.8 \%$ after ten cycles. As a matter of fact, the behaviour of this four times dip-coated specimen reproduces accurately that of the NiPtAl bond coated specimen for the three investigated cycles. Conversely the specimen filled-in with 8 dip-coatings does not show any improvement in terms of extent of spallation following the exposure to two, six and ten oxidation cycles. Though cracks were better closed as dip-coatings were accumulated, the over thickness deposited on top of the remaining TBC fails easily upon cycling as expected.

\section{Conclusion}

After a brief review of the elementary microstructural mechanisms specifically responsible for the degradation of sol-gel Thermal Barrier Coatings exposed to cyclic oxidation through a synergetic effect of crack initiation, crack propagation and coalescence and ultimately full detachment of individual spalls; the feasibility of controlling and stabilising the initial crack network was investigated. The crack network can either develop during processing for thick TBCs or during the very first time of oxidation exposure for thin TBCs.

Namely, the post-treatment of properly heat-treated, as-deposited sol-gel TBCs by additional dip-coatings is successfully used to fill in processed induced crack and significantly enhance the cyclic oxidation life of the TBC. It is shown that, fortuitously, the behaviour of filled TBCs deposited on NiAl bond-coated substrates is similar to that of highly adherent unfilled TBCs deposited on NiPtAl bond-coated substrates. The improvement in cyclic oxidation behaviour related to a proper reinforcement and stabilisation of the cracks is attributed to the adequate formulation of the filling sol and the optimum number of dip-coatings chosen to exhibit the best compromise between a satisfactory filling and a non occurrence of a poorly adherent overlayer brought up during processing. However, this technique, which can be promisingly considered as a cost-efficient, technically attractive repair technique to enhance service life of TBCs, still suffers some limitations. Indeed, the directionality of the dip-coating process results in a non-uniform, asymmetric filling of cracks. In addition, the concomitance of the crack filling and the deposition of an over layer at the surface of the non-cracked parts of the TBCs, drastically limits the number of feasible dip-coatings and correlatively the efficiency of the filling itself. Consequently, further research will be conducted to check whether non-directional techniques such as spray coating for instance, could beneficially promote the occurrence of more symmetric, more uniform filling of defects.

\section{Acknowledgment}

Authors gratefully acknowledge Safran (Snecma) for providing bond-coated superalloys substrates.

\section{References}

[1] U. Schulz, C. Leyens, K. Fritscher, M. Peters, B. Saruhan-Brings, O. Lavigne, J.M. Dorvaux, M. Poulain, R. Mévrel, M. Caliez, Aerosp. Sci. Tech. 7 (2003) 73.

[2] A.G. Evans, D.R. Mumm, JW. Hutchinson, G.H. Meier, F.S. Pettit, Prog Mater. Sci. 46 (2001) 505

[3] C. Viazzi, R. Wellman, D. Oquab, J. Nicholls, D. Monceau, J.P. Bonino, F. Ansart, Mater. Sci. Forum 3 (2008) 595.

[4] J. Sniezewski, Y. Le Maoult, P. Lours, L. Pin, V. Menvie Bekale, D. Monceau, D. Oquab, J. Fenech, F. Ansart, J.-P. Bonino, Surf. Coat. Tech. 205 (2010) 1256.

[5] J. Sniezewski, Y. Le Maoult, P. Lours, Mater. at High Temp. 27 (2010) 101.

[6] C. Viazzi, A. Deboni, J.Z. Ferreira, J.P. Bonino, F. Ansart, Solid State Sci. 8 (2006) 1023.

[7] M. Shane, M.L. Mecartney, J. Mater. Sci. 25 (1990) 1537.

[8] J. Fenech, C. Viazzi, J.-P. Bonino, F. Ansart, A. Barnabé, Ceramics Intern. 35 (2009) 3427.

[9] P. Cai, J.D. Green, G.L. Messing, J. Am. Ceramic Society 80 (1997) 1929.

[10] J.R. Nicholls, JOM-J. Miner. Metals \& Mater. Society 52 (2000) 28.

[11] R. Streiff, D.H. Boone, J. Mater. Engr. 10 (1988) 15.

[12] A.L. Purvis, B.M. Warnes, Surface \& Coat. Tech. 146-147 (2001) 1

[13] N. Vialas, D. Monceau, Surface \& Coat. Tech. 201 (2006) 3846.

[14] T. Xu, M.Y. He, A.G. Evans, Acta Materialia 201 (2003) 3807

[15] L. Pin, F. Ansart, J. Fenech, P. Lours, J.P. Bonino, J. Sniezewski, Y. Le Maoult, Adv. Sci. Tech. 66 (2010) 136. 